\title{
Mobile-based Tajwid 1 Learning Media at the Gontor Entrance Guidance Institution with the Demonstration Method
}

\section{Media Pembelajaran Berbasis Mobile Tajwid 1 Pada Lembaga Bimbingan Masuk Gontor Dengan Metode Demonstrasi}

\author{
Muhammad Sirajuddin Mumtaz Dzaky ${ }^{1}$, Dihin Muriyatmoko ${ }^{2}$, Taufiqurrahman ${ }^{3}$ \\ \{ sirajuddin@mhs.unida.gontor.ac.id, dihin@unida.gontor.ac.id ${ }^{2}$, taufiqurrahman@unida.gontor.ac.id ${ }^{3}$ \}
}

Teknik Informatika, Universitas Darussalam Gontor

\begin{abstract}
Darussalam Gontor Modern Boarding School (PMDG) graduates established tutoring institutions in their respective regions. The institution is called Bimbingan Masuk Gontor (Bimago). Currently, prospective students who want to enter Gontor have difficulty learning Tajwid 1 because of the limited learning media that still use printed books and the number is limited. This requires other media, one of which is a smartphone. The purpose of this research is to facilitate prospective students who want to learn the PMDG version of Tajweed 1. This study uses a Software Development Life Cycle approach and applies a demonstration method to its content. Application testing is done in 4 ways. With the blackbox method, it shows the application is running smoothly. The use of hardware with 5 smartphones of various brands and a screen size of at least 5.20 inches indicates the application is running well. A learning media expert gave an average of $94.38 \%$. Six Tajwid teachers gave a score of $88.40 \%$. The results of this study can be concluded that this application can help as an effective learning tool.
\end{abstract}

Keywords - Darussalam Gontor Modern Boarding School; Learning Media; Mobile; Tajwid 1 application

\begin{abstract}
Abstrak. Lulusan Pondok Modern Darussalam Gontor (PMDG) mendirikan lembaga bimbingan belajar di daerahnya masing-masing. Lembaga tersebut dinamakan Lembaga Bimbingan Masuk Gontor (Bimago). Saat ini, calon santri yang ingin masuk Gontor kesulitan dalam belajar Tajwid 1 karena terbatasnya media belajar yang masih menggunakan buku cetak dan jumlahnya terbatas. Untuk itu dibutuhkan media lain, salah satunya smartphone. Tujuan penelitian ini untuk mempermudah calon santri yang ingin mempelajari Tajwid 1 versi PMDG. Penelitian ini menggunakan pendekatan metode Software Development Life Cycle dan menerapkan metode demonstrasi pada kontennya. Pengujian aplikasi dilakukan dengan 4 cara. Dengan metode blackbox menunjukkan aplikasi sudah berjalan lancar. Penggunaan perangkat keras dengan 5 smartphone berbagai merk dan ukuran layar minimal 5.20 inci menunjukkan aplikasi berjalan dengan baik. Seorang ahli media pembelajaran memberikan rata-rata $94.38 \%$. Enam orang guru Tajwid memberikan nilai $88.40 \%$. Hasil penelitian ini dapat disimpulan bahwa aplikasi ini dapat membantu sebagai sarana pembelajaran yang efektif.
\end{abstract}

Kata Kunci - Pondok Modern Darussalam Gontor; Media pembelajaran; Mobile; aplikasi tajwid 1

\section{Pendahuluan}

Teknologi komunikasi via smartphone, saat ini sudah jauh melebihi fungsi awalnya. Hal itu disebabkan karena berkembangnya sistem operasi yang semakin canggih. Diantara sistem operasi tersebut adalah Android. Sistem operasi Android tersebut mampu meningkatkan pengalaman pengguna lebih baik dibandingkan dengan system operasi lainnya [1]. Diantara kemampuan Android adalah bisa digunakan sebagai alat bantu untuk beribadah membaca AlQur'an [2][3].

Membaca Al-Qur'an adalah satu satu bentuk ibadan umat Islam untuk mendekatkan diri kepada Tuhan. Untuk memahami isi dari kandungan Al-Qur'an tidak cukup hanya dengan membaca huruf demi huruf saja. Rasulullah SAW menjelaskan bahwa untuk tahsinul qiraat membutuhkan penuntun ilmu, diantaranya adalah ilmu tajwid. Menurut Bahasa Tajwid adalah mashdar dari jawwada-yujawwidu, yang berarti membaguskan. Sedangkan menurut istilah menyatakan bahwa ilmu tajwid merupakan ilmu tentang kaidah dan cara membaca Al-Qur'an dengan benar. Ilmu tajwid bertujuan untuk memelihara bacaan Al-Qur'an dan menghindarkan dari kesalahan, perubahan dan memelihara lisan dari ketidak benaran bacaan. Hukum belajar ilmu tajwid bagi seorang muslim adalah fardhu kifayah. Sedangkan hukum membaca Al-Qur'an secara baik (sesuai aturan ilmu tajwid) adalah fardhu 'ain [4].

Buku Pembelajaran Tajwid Jilid 1 karya KH Imam Zarkasyi digunakan di berbagai pondok pesantren modern, utamanya di Pondok Modern Darussalam Gontor (PMDG), Ponorogo, Jawa Timur Indonesia. Buku ini sampai sekarang masih digunakan untuk pengajaran pada kelas 1 KMI karna bersifat ilmu dasar. Buku ini dijadikan 
Procedia of Engineering and Life Science Vol.1 No. 1 March 2021

Seminar Nasional \& Call for Paper Fakultas Sains dan Teknologi (SENASAINS $1^{\text {st }}$ ) Universitas Muhammadiyah Sidoarjo

pembelajaran para santri untuk mengetahui ilmu tajwid supaya terhindar dari kesalahan-kesalahan dalam membaca Al-Qur'an sehingga mampu membaca Al-Qur'an dengan baik dan benar [5].

Salah satu bentuk alat bantu pembelajaran disebut media pembelajaran. Maknanya adalah apa saja yang dapat dimanfaatkan untuk menumbuhkan perhatian, perasaan, pikiran dan ketrampilan siswa sehingga dapat mengarahkan proses belajar. Salah satu media pembelajaran adalah alat berupa fisik yang dimanfaatkan sebagai alat untuk menyampaikan materi pelajaran. Diantaranya tape recorder, video recorder, film, kaset, buku, video camera, foto, grafik, komputer dan televisi [6].

Ilmu tajwid merupakan salah satu materi ujian lisan bagi calon pelajar yang hendak masuk di PMDG. Semenjak tahun 2014, PMDG tidak mengadakan bimbingan belajar untuk calon pelajar dikarenakan alasan tertentu, yang menjadikan calon pelajar bingung dalam mencari bimbingan belajar agar lulus tes ujian masuk PMDG. Bersama berjalannya waktu, alumni PMDG berinisiatif mengadakan bimbingan belajar untuk calon pelajar di daerah masingmasing atau perkonsulat yang disebut BIMAGO yaitu Bimbingan Masuk Gontor. Calon pelajar yang ingin masuk PMDG tidak semuanya lulus ujian lisan, salah satunya dikarenakan faktor kesulitan pada pelajaran tajwid. Pembelajaran tajwid di Lembaga BIMAGO saat ini mengunakan buku cetak yang jumlahnya terbatas sehingga menyulitkan untuk mempelajarinya. Sehingga diperlukan cara untuk mendukung bimbingan belajar ini, membatu pelajar agar bisa otodidak (belajar sendiri), memberikan pengetahuan, dan menambah ketertarikan pelajar dalam pelajaran tajwid. Maka dari itu dibutuhkan model Pembelajaran Tajwid yang menarik dan dapat digunakan kapan saja dan di mana saja.

\section{METODE}

Metode pembelajaran yang digunakan pada aplikasi Tajwid 1 ini adalah metode demonstrasi. Metode demonstrasi dapat memperlihatkan proses terjadinya suatu kejadian atau tingkah laku yang dicontohkan agar dapat dipahami dan diketahui oleh siswa baik tiruannya maupun secara nyata. Nabi Muhammad SAW mengajarkan praktek agama sebagai pendidik untuk umatnya menggunakan metode Demonstrasi ini. Diantaranya mengajarkan cara sholat berwudhu', haji, puasa dan berzakat. Kemudian barulah umatnya menirukannya. Dalam sebuah hadits Rasulullah bersabda :

"Sholatlah kamu sebagaimana kamu melihat Aku mendirikan sholat”(HR. Bukhari 7246) [7].

Bila kita perhatikan hadits tersebut, maka kebenaran bahwa cara-cara sholat tersebut pernah dipraktekkan dan didemonstrasikan oleh Nabi Muhammad SAW.

Metode demonstrasi juga disebut sebagai metode mengajar dengan cara mempraktekkan urutan, aturan, kejadian untuk melakukan kegiatan, baik langsung maupun dengan media pembelajaran yang sesuai dengan tema yang dibahas dan materi yang sudah diberikan. Metode tersebut dimanfaatkan supaya siswa lebih memahami materi yang disampaikan karena penggunaan alat peraga langsung dan menggunakan alat media visualisasi yang bisa menolong siswa untuk memahami materi [8].

Metode rancangan sistem pada perancangan Aplikasi Tajwid 1 ini menggunakan metode Software Development Life Cycle (SDLC). Ada 6 tahapan utama dalam metode SDLC yaitu: analisis kebutuhan sistem, desain, konstruksi, implementasi, pengetesan, dan perawatan.

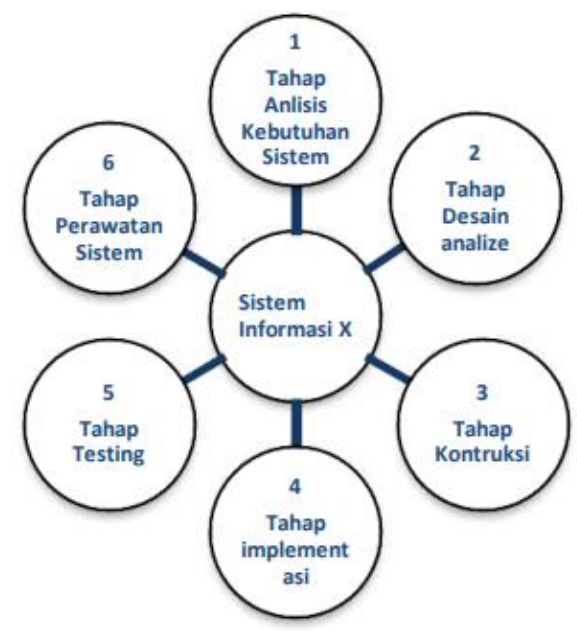

Gambar 1. Metode SDLC [9]

\section{A. Analisis kebutuhan}

Tahap ini dilakukan untuk menentukan apa saja yang dibutuhkan untuk merancang dan membuat sebuah sistem informasi, dan memerlukan proses pengumpulan data guna melaksanakan penelitian dengan menggunakan metode pengumpulan data atau metode untuk memperoleh informasi yang dibutuhkan dalam rangka mencapai tujuan 
Procedia of Engineering and Life Science Vol.1 No. 1 March 2021

Seminar Nasional \& Call for Paper Fakultas Sains dan Teknologi (SENASAINS $1^{\text {st }}$ )

Universitas Muhammadiyah Sidoarjo

penelitian [10]. Kebutuhan dan batasan software harus telah terdefinisi. Informasi ini didapat melalui analisis, wawancara, atau penyebaran kuesioner. Berikut kebutuhan penelitian yang diperlukan setelah melakukan tahapan identifikasi.

Tabel 1. Kebutuhan Aplikasi

\begin{tabular}{cll}
\hline No & \multicolumn{1}{c}{ Kegiatan } & \multicolumn{2}{c}{ Hasil } \\
\hline 1 & Identifikasi masalah & $\begin{array}{l}\text { Calon pelajar membutuhkan Pembelajaran Tajwid untuk ujian lisan } \\
\text { di Pondok Modern Darussalam Gontor. }\end{array}$ \\
\hline 2 & Isi dari aplikasi & $\begin{array}{l}\text { Imu tajwid dari buku pelajaran tajwid qaidah bagaimana mestinya } \\
\text { membaca Al-Qur'an untuk pelajaran permulaan Kulliyatu-1- } \\
\text { Mu'allimin al-islamiyah. }\end{array}$ \\
\hline 3 & Metode Pengajaran & Metode demonstrasi \\
\hline 4 & Solusi yang ditawarkan & $\begin{array}{l}\text { Aplikasi mobile media pembelajaran tajwid jilid 1 lembaga } \\
\text { bimbingan masuk gontor. }\end{array}$ \\
\hline 5 & Teknologi yang digunakan & $\begin{array}{l}\text { Media pembelajaran tajwid 1 berbasis mobile dengan bahasa } \\
\text { pemograman Java }\end{array}$ \\
\hline
\end{tabular}

\section{B. Desain sistem}

Fase ini adalah pembuatan desain berdasarkan pada kebutuhan perangkat lunak untuk di implementasikan. Tahap desain sistem bertujuan untuk membuat spesifikasi dari komponen sistem informasi agar sesuai dengan tahap analisis. Use Case Diagram adalah visualisai skenario interaksi antara user dan sistem. Sebuah diagram use case menjelaskan hubungan antara aktor dan aktifitas aktor yang dapat dikerjasakn oleh aplikasi. Berikut ini merupakan gambaran $u s e$ case diagram pengguna aplikasi tajwid jilid 1 pada gambar 2.

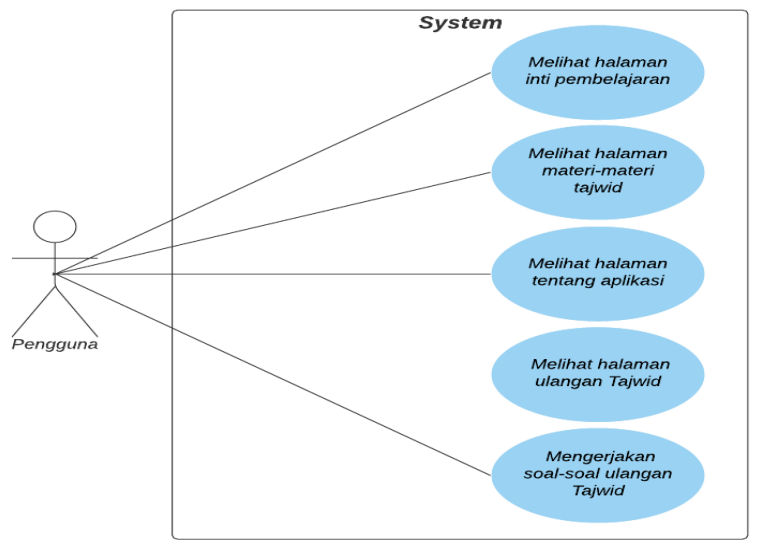

Gambar 2. Use Case Diagram Pengguna Aplikasi Tajwid 1

Alur proses aplikasi digambarkan dengan Activity Diagram agar memudahkan tahapan implementasi aplikasi. Berikut Activity Diagram aplikasi yang akan dibangun tertera pada gambar 3.

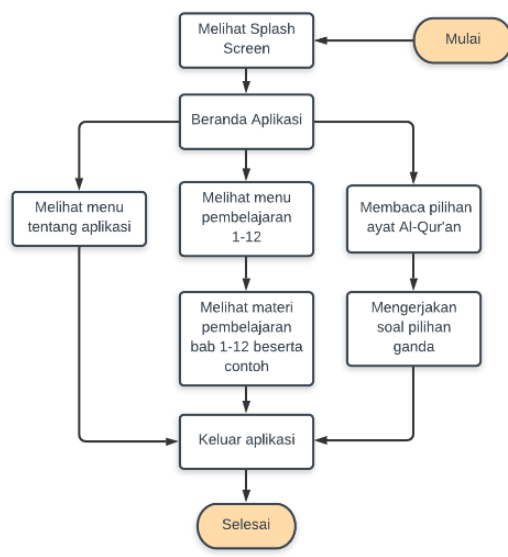

Gambar 3. Activity Diagram Alur Proses Aplikasi 


\section{Konstruksi}

Tahap konstruksi merupakan tahap pengkodean program yang menggunakan IDE (Integrated Development Environment) yaitu android studio dengan menggunakan bahasa pemrograman Java sebagai backend yang menjalankan fungsi-fungsi pada system dan XML (Extended Markup Language) sebagai user interface.

\section{Implementasi}

Tahap implementasi ini meliputi menjalankan/implementasi program pada smartphone dengan sistem operasi android dan menghasilkan tampilan aplikasi dari desain system yang telah dilakukan pada tahap sebelumnya.

\section{E. Testing}

Pada tahap ini, merupakan tahap akhir pada pembuatan sistem. Yaitu tahapan pengetesan yang dilakukan oleh pengguna. Pengguna akan menguji aplikasi sudah sesuai dengan kebutuhan pengguna. Tahapan ini dijelaskan di bab hasil.

\section{F. Perawatan}

Tahap perawatan adalah fase terakhir pada model ini, aplikasi yang sudah jadi dilakukan pemeliharaan dan perbaikan kekurangam dari masukan pengguna. Pengguna dapat melakukan feedback dengan menghubungi email pengembang atau ulasan yang sudah tertera di playstore.

\section{HaSil dan Pembahasan}

Berdasarkan tahapan-tahapan yang dilakukan pada saat Analisa dan perancangan system maka dalam tahapan selanjutya yaitu tahapan implementasi diperoleh hasil Aplikasi Pelajaran Tajwid yang berfungsi untuk membantu calon pelajar / santri dalam belajar tajwid untuk ujian masuk PMDG. Berikut adalah interface atau tampilan dari aplikasi Tajwid 1 seperti pada Gambar 4:

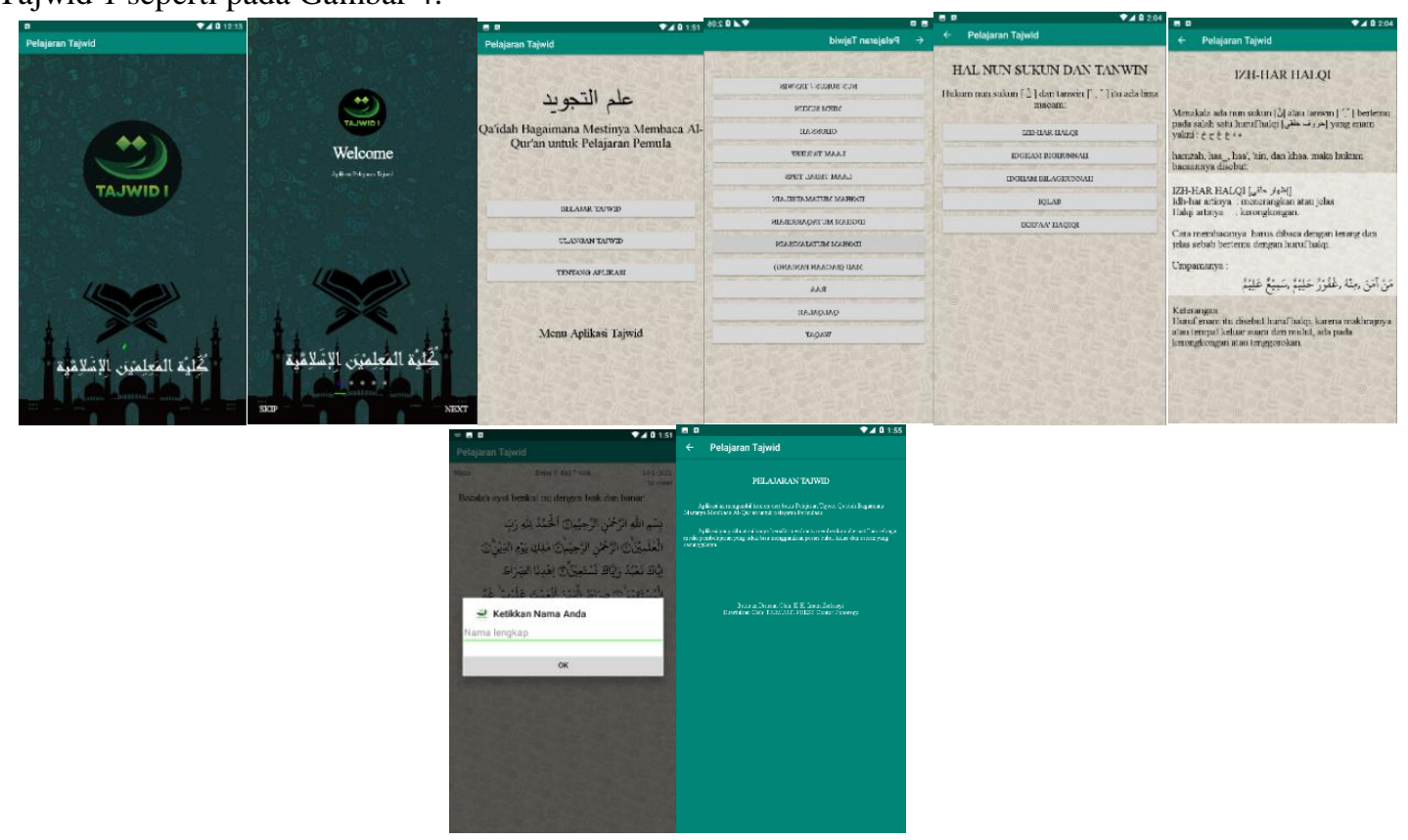

Gambar 4. Interface Aplikasi Tajwid 1

Aplikasi yang sudah dirancang dan dibangun perlu diujicobakan melalui beberapa proses. Proses pengujian aplikasi tajwid 1 diutamakan pada pengujian funsional, maka metode uji yang digunakan adalah Blackbox Testing. Blackbox Testing berpusat pada spek fungsi dari software. Tester merupakan kumpulan keadaan input dan melakukan tes data pada fungsi spek program [11].

\section{A. Rekap pengujian black box}

Berikut adalah rekapan hasil pengujian untuk menu-menu atau fitur-fitur yang ada dan dikembangkan dalam aplikasi Tajwid 1 ini.

Tabel 2. Rekapan hasil pengujian aplikasi Tajwid 1 
Procedia of Engineering and Life Science Vol.1 No. 1 March 2021

Seminar Nasional \& Call for Paper Fakultas Sains dan Teknologi (SENASAINS $1^{\text {st }}$ ) Universitas Muhammadiyah Sidoarjo

\begin{tabular}{|c|c|c|c|c|c|}
\hline No & $\begin{array}{l}\text { Skenario } \\
\text { Pengujian }\end{array}$ & Kasus Pengujian & $\begin{array}{l}\text { Hasil yang } \\
\text { diharapkan }\end{array}$ & Hasil Pengujian & Status \\
\hline 1 & $\begin{array}{l}\text { Pengujian tombol } \\
\text { pada Splash } \\
\text { Screen }\end{array}$ & $\begin{array}{l}\text { Menekan tombol } \\
\text { mengerti pada } \\
\text { splash screen }\end{array}$ & $\begin{array}{l}\text { Masuk ke beranda } \\
\text { aplikasi. }\end{array}$ & Sesuai & Valid \\
\hline \multirow[t]{4}{*}{2} & \multirow[t]{4}{*}{$\begin{array}{l}\text { Pengujian fitur } \\
\text { Welcome Screen }\end{array}$} & $\begin{array}{l}\text { Menggeser halaman } \\
\text { Welcome Screen }\end{array}$ & $\begin{array}{l}\text { Gambar dan } \\
\text { penjelasan singkat } \\
\text { dapat tergeser ke } \\
\text { welcome screen } \\
\text { selanjutnya. }\end{array}$ & Sesuai & Valid \\
\hline & & $\begin{array}{l}\text { Menekan tombol } \\
\text { next pada welcome } \\
\text { screen }\end{array}$ & $\begin{array}{l}\text { Welcome screen } \\
\text { dapat bergeser ke } \\
\text { halaman selanjutnya. }\end{array}$ & Sesuai & Valid \\
\hline & & $\begin{array}{l}\text { Menekan tombol } \\
\text { skip pada welcome } \\
\text { screen }\end{array}$ & $\begin{array}{l}\text { Langsung } \\
\text { menampilkan } \\
\text { beranda aplikasi. }\end{array}$ & Sesuai & Valid \\
\hline & & $\begin{array}{l}\text { Menekan tombol } \\
\text { start pada akhir } \\
\text { welcome screen }\end{array}$ & $\begin{array}{l}\text { Masuk ke baranda } \\
\text { aplikasi. }\end{array}$ & Sesuai & Valid \\
\hline \multirow[t]{3}{*}{3} & \multirow[t]{3}{*}{$\begin{array}{l}\text { Pengujian fitur } \\
\text { Beranda Aplikasi }\end{array}$} & $\begin{array}{l}\text { Menekan tombol } \\
\text { menu belajar tajwid }\end{array}$ & $\begin{array}{l}\text { Menampilkan menu } \\
\text { pembelajaran tajwid } \\
\text { Bab 1-12. }\end{array}$ & Sesuai & Valid \\
\hline & & $\begin{array}{l}\text { Menekan tombol } \\
\text { menu tentang } \\
\text { aplikasi }\end{array}$ & $\begin{array}{l}\text { Menampilkan } \\
\text { halaman ikhtisar } \\
\text { aplikasi. }\end{array}$ & Sesuai & valid \\
\hline & & $\begin{array}{l}\text { Menekan tombol } \\
\text { Ulangan/Ujian Al- } \\
\text { Qur'an }\end{array}$ & $\begin{array}{l}\text { Masuk ke halaman } \\
\text { ulangan. }\end{array}$ & Sesuai & Valid \\
\hline \multirow[t]{2}{*}{4} & \multirow[t]{2}{*}{$\begin{array}{l}\text { Pengujian fitur } \\
\text { Menu Belajar } \\
\text { Tajwid }\end{array}$} & $\begin{array}{l}\text { Menekan tombol } \\
\text { bab 1-12 }\end{array}$ & $\begin{array}{l}\text { Masuk ke setiap } \\
\text { halaman } \\
\text { pembelajaran tajwid } \\
\text { bab } 1-12 \text { dan } \\
\text { menampilkan menu } \\
\text { sub bab jika } \\
\text { memilikinya. }\end{array}$ & Sesuai & Valid \\
\hline & & $\begin{array}{l}\text { Menekan tombol } \\
\text { back pada actionbar }\end{array}$ & $\begin{array}{l}\text { Dapat Kembali ke } \\
\text { halaman beranda. }\end{array}$ & Sesuai & valid \\
\hline \multirow[t]{2}{*}{5} & \multirow{2}{*}{$\begin{array}{l}\text { Pengujian fitur } \\
\text { sub bab } \\
\text { pembelajaran } \\
\text { tajwid }\end{array}$} & $\begin{array}{l}\text { Menekan tombol } \\
\text { sub bab pilihan }\end{array}$ & $\begin{array}{l}\text { Masuk ke halaman } \\
\text { sub bab yang dipilih. }\end{array}$ & Sesuai & Valid \\
\hline & & $\begin{array}{l}\text { Menekan tombol } \\
\text { back }\end{array}$ & $\begin{array}{l}\text { Kembali ke halaman } \\
\text { menu belajar tajwid. }\end{array}$ & Sesuai & valid \\
\hline 6 & $\begin{array}{l}\text { Pengujian fitur } \\
\text { halaman materi } \\
\text { pembelajaran }\end{array}$ & $\begin{array}{l}\text { Menekan contoh } \\
\text { materi tajwid }\end{array}$ & $\begin{array}{l}\text { Mengeluarkan suara } \\
\text { sesuai dengan contoh } \\
\text { pada materi. }\end{array}$ & Sesuai & Valid \\
\hline \multirow[t]{4}{*}{7} & \multirow[t]{4}{*}{$\begin{array}{l}\text { Pengujian fitur } \\
\text { halaman Ulangan } \\
\text { /Ujian Al-Qur'an }\end{array}$} & $\begin{array}{l}\text { Mengisikan nama } \\
\text { pada pop-up } \\
\text { sebelum memulai } \\
\text { ujian }\end{array}$ & $\begin{array}{l}\text { Nama dapat terisi dan } \\
\text { ditampilkan pada } \\
\text { pojok kiri atas } \\
\text { halaman. }\end{array}$ & Sesuai & valid \\
\hline & & $\begin{array}{l}\text { Menekan tombol } \\
\text { selesai membaca }\end{array}$ & $\begin{array}{l}\text { Memunculkan soal } \\
\text { pilihan ganda untuk } \\
\text { ujian }\end{array}$ & Sesuai & valid \\
\hline & & $\begin{array}{l}\text { Memilih salah satu } \\
\text { soal pilihan ganda }\end{array}$ & $\begin{array}{l}\text { Muncul toast jawaban } \\
\text { benar jika benar dan } \\
\text { jawaban salah jika } \\
\text { salah }\end{array}$ & Sesuai & valid \\
\hline & & $\begin{array}{l}\text { Menghitung hasil } \\
\text { ujian dari jawaban } \\
\text { yang benar dan } \\
\text { salah }\end{array}$ & $\begin{array}{l}\text { Menampilkan jumlah } \\
\text { dari jawaban yang } \\
\text { benar dan salah }\end{array}$ & Sesuai & valid \\
\hline
\end{tabular}


Procedia of Engineering and Life Science Vol.1 No. 1 March 2021

Seminar Nasional \& Call for Paper Fakultas Sains dan Teknologi (SENASAINS 1st)

Universitas Muhammadiyah Sidoarjo

Pengujian sistem dilakukan guna mengetahui kesalahan yang tidak ditemukan ketika proses pengembangan. Pengujian dilakukan menggunakan metode Blackbox, dan menghasilkan kesimpulan bahwa semua fungsi yang terdapat pada setiap halaman dan aktivitas sistem dapat berfungsi sebagaimana mestinya.

Pengujian selanjutnya adalah pengujian fungsionalitas software yang telah dilakukan menggunakan beberapa media handphone atau smartphone untuk memeriksa apakah aplikasi sudah betul-betul dapat berjalan dengan sistem operasi Android, media tersebut diantaranya adalah:

Tabel 3. Media Pengujian

\begin{tabular}{lllll}
\hline No. & Merek Hp & Android versi & Ukuran layar & Ket. \\
\hline 1 & Redmi Note 3 & Android 6.0.1 & 5.50 inci & Berhasil \\
2 & Oppo F9 & Android 10 & 6.30 inci & Berhasil \\
3 & Vivo Y55s & Android 6.0 & 5.20 inci & Berhasil \\
4 & Samsung J7 & Android 8.0 & 5.50 inci & Berhasil \\
5 & Realme 3 & Android 10 & 6.22 inci & Berhasil \\
\hline
\end{tabular}

Setelah menggunakan 5 media ini, pengujian fungsionalitas dengan resolusi yang berbeda-beda menunjukkan aplikasi Tajwid 1 dapat berjalan dengan baik pada kelima media tersebut.

Setelah terbuatnya aplikasi, maka dilakukan pengujian dengan menyebarkan kuisioner kepada pengguna bertujuan untuk memastikan bahwa sistem yang dibangun dapat diterima dan sesuai dengan kebutuhan pengguuna. Responden dibagikan kepada guru tajwid, dan calon pelajar bimbingan masuk Gontor. Responden menilai sistem dari pengalaman mereka selama melakukan uji coba aplikasi. Untuk mengumpulkan tanggapan dan penilaian dari pengguna, peneliti menggunakan 10 pertanyaan kepada masing-masing responden. Dari penghitungan rata-rata tanggapan setiap responden, diperoleh nilai $90.33 \%$ dari guru tajwid dan 86,8\% dari calon pelajar bimbingan masuk Gontor yang mempunyai kesimpulan bahwa pengguna atau para responden merasa PUAS terhadap sistem yang dibangun.

\section{KESIMPULAN}

Dengan semua pengujian dan hasil penyebaran kuisioner yang telah dilakukan, aplikasi Tajwid 1 dinyatakan telah memenuhi kriteria dan dinyatakan efektif sebagai media pembelajaran berbasis mobile. Hasil penelitian menunjukkan bahwa aplikasi ini dapat membantu dalam sarana pembelajaran tajwid akan tetapi aplikasi ini hanya bersifat membantu, dan tidak bisa menggantikan peran guru serta interaksi antar guru dengan murid yang sesungguhnya. Diharapkan untuk pengembang yang selanjutnya agar menyediakan aplikasi ini untuk pengguna iOS (iPhone), menambah fitur baru berupa penerapan pada pengajaran materi Al-Qur'an, dan menambahkan gambar interaktif pada aplikasi.

\section{REFERENSI}

[1] V. Maarif, H. M. Nur, and W. Rahayu, "APLIKASI PEMBELAJARAN ILMU TAJWID BERBASIS ANDROID,” Evolusi J. Sains dan Manaj., vol. 6, no. 1, pp. 56-65, Mar. 2018, doi: 10.31294/evolusi.v6i1.3586.

[2] S. Herman, S. Samsuni, and F. Fathurohman, "PENGEMBANGAN SISTEM MEMBACA AL-QUR'AN DENGAN METODE MULTIMEDIA DEVELOPMENT LIFE CYCLE,” Ilk. J. Ilm., vol. 11, no. 2, pp. 95-101, Sep. 2019, doi: 10.33096/ilkom.v11i2.406.95-101.

[3] E. Rahmawati and E. Abdulmanan, "Pemodelan Aplikasi Dunia Islam Mengaji Berbasis Android," JITK (Jurnal Ilmu Pengetah. dan Teknol. Komputer), vol. 4, no. 2, pp. 197-20, 2019, [Online]. Available: http://www.nusamandiri.ac.id.

[4] Imam Zarkasyi, "Pelajaran Tajwid Jilid I," Gontor Ponorogo, vol. Trimurti P, p. Hal 1-3, 1995.

[5] D. Muriyatmoko, A. F. Abdullah, Z. A. Musyafae, Z. A. Musyafa, A. Farouq Abdullah, and Z. Adhiim Musyafa', "Durus Al-Lughah Gontory: Interactive Arabic Mobile Learning for Beginners," IJITEE (International J. Inf. Technol. Electr. Eng., vol. 2, no. 1, p. 8, Jul. 2018, doi: 10.22146/ijitee.36641.

[6] D. Muriyatmoko, F. R. Pradhana, and Z. A. Musyafa, "Durus Al-Lughah Gontory: Media Pembelajaran Bahasa Arab untuk Pemula Menggunakan Metode Langsung," J. Teknol. Inf. dan Ilmu Komput., vol. 6, no. 1, pp. 7784, 2019.

[7] 2012. Bukhari Umar, 1959-; Achmad Zirzis; Bukhari Umar; Nur Laily Nusroh. Hadis tarbawi : pendidikan dalam perspektif hadis / penulis, Bukhari Umar; editor, Achmad Zirzis, Nur Laily Nusroh. Jakarta :: Amzah, "DetailOpac@opac.perpusnas.go.id.”.

[8] N. Aeni and D. S. Yuhandini, "Pengaruh Pendidikan Kesehatan Dengan Media Video Dan Metode Demonstrasi Terhadap Pengetahuan SADARI," Care J. Ilm. Ilmu Kesehat., vol. 6, no. 2, p. 162, 2018, doi: 10.33366/cr.v6i2.929.

[9] Y. S. Dwanoko, "Implementasi Software Development Life Cycle ( Sdlc ) Dalam Penerapan Pembangunan 
Procedia of Engineering and Life Science Vol.1 No. 1 March 2021

Seminar Nasional \& Call for Paper Fakultas Sains dan Teknologi (SENASAINS $1^{\text {st }}$ )

Universitas Muhammadiyah Sidoarjo

Aplikasi Perangkat,” J. Teknol. Inf., vol. 7, no. 2, pp. 83-94, 2016.

[10] Winarno, Metodologi Penelitian Dalam Pendidikan Jasmani, no. January. Malang: Penerbit Universitas Negri Malang (UM Press), 2013.

[11] M. S. Mustaqbal, R. F. Firdaus, and H. Rahmadi, "PENGUJIAN APLIKASI MENGGUNAKAN BLACK BOX TESTING BOUNDARY VALUE ANALYSIS ( Studi Kasus : Aplikasi Prediksi Kelulusan SNMPTN )," J. Ilm. Teknol. Inf. Terap., vol. I, no. 3, pp. 31-36, 2015, doi: https://doi.org/10.33197/jitter.vol1.iss3.2015.62. 